\title{
Editorial
}

Massimo Ferrari and Sebastian Luft

\section{Cassirer's Children, Special Topics Issue, JTPH, Vol. II/2021}

https://doi.org/10.1515/itph-2021-0010

The papers collected in this Special Topics issue, titled "Cassirer's Children," go back to a conference (Humboldt-Kolleg, funded by the Alexander von Humboldt Foundation) organized by Ferrari and Luft in Torino in the spring of 2018. ${ }^{1}$

A few words are in order to explain the rationale of this volume's special topic and its theme. The topic, “Cassirer's Children," might strike some as odd or unusual. Are we now in the business of talking about a philosopher's offspring, much like one talks of, say, musical legacies?

It is of course trivial to say that the term "children" is not to be understood in the biological sense. And in fact, for those who do not immediately recognize it, the title is an allusion to another book. It is a reference to the title of a book by the intellectual historian Richard Wolin. His much-read book of 2001 (reissued in 2015) was provocatively entitled "Heidegger's Children." The children Wolin specifically meant (since one presumably could have selected others) were Hannah Arendt, Karl Löwith, Hans Jonas, and Herbert Marcuse. The book made a big splash at the time, not least because Wolin chose as children, apart from their own philosophical merits, students who were all of Jewish origin, knowing of their teacher's (as we know now) rabid Anti-Semitism. Wolin's point was, among others, that Heidegger, apart from being one of the most important philosophers of the $20^{\text {th }}$ century, was also a gifted teacher who generated a following of philosophers who, in their own right, followed in the master's footsteps.

1 The speakers at this conference were, besides the authors here, Muriel van Vliet (who spoke on Edgar Wind), Andrea Staiti (on Hans Blumenberg) and Sebastian Luft (who focused on Clifford Geertz). Following the policy of the Journal, the editors of this journal will refrain from publishing texts in this venue (this pertains to the papers by Staiti and Luft).

Sebastian Luft, Department of Philosophy, Marquette University, Marquette Hall, Milwaukee 53201, Wisconsin, USA, E-mail: sebastian.luft@marquette.edu

Massimo Ferrari, Department of Philosophy and Education Sciences, University of Turin, Via S. Ottavio, 20, 10124 Torino, Italy 
Heidegger, as we know, survived the Third Reich and the Second World War nearly unscathed, to witness after the War a surge of interest in his work and dying a peaceful death in 1976 as an octogenarian. Indeed, looking back at the time after the war, Heidegger was literally the only philosopher of his generation who held out in Germany and experienced any reception of his work. Everybody else had either emigrated or passed away (or worse, was killed at the hand of the Nazis). It took a whole new generation of philosophers in Germany who had to come of age after the war to displace Heidegger. But this is not how the situation was just few years earlier. As a matter of fact, looking back at the time (the 20s and 30s and even 40s), there was especially one philosopher who stood out among the big names in European philosophy, a time in which Europe was not poor in big names in philosophy, and this person was Ernst Cassirer. Seemingly eclipsed after World War II by Heidegger and other existentialists, this obscures the fact that Ernst Cassirer was at the time and now (in hindsight) is, beyond a doubt, also considered one of the most important philosophers of the twentieth century. Cassirer died in the streets of New York in 1945 at the age of 70, after he had just escaped once more from the Nazis, after emigrating first to England, then to Sweden, cutting short, in effect, any further influence he might have had in the New World.

Now one of the ways the importance of philosophers can be assessed is by viewing their effect on subsequent scholars, either through direct mentorship or mediately through the reception of their work. Cassirer passed, as mentioned, in 1945 at the premature age of 70, after having just begun a new teaching appointment at Columbia University, after having to move yet again upon spending two years at Yale University, and before that from Sweden and before that from England. But during his tenures as professor at the Universities of Hamburg (1919-1933), Oxford (1933-1935), Göteborg (1935-1941), Yale (1941-1944) and finally Columbia (19441945), and prior to his untimely death, not only was Cassirer able to make a mark on scholarship of his host countries; in addition, he exerted significant (but not always obvious) influence on several generations of students, many of whom went on to have distinguished scholarly careers of their own. It is this lineage of thought which, the editors believe, has not sufficiently been investigated thus far.

Indeed, one can speculate that the history of twentieth century philosophy (and with it, the entire scholarly landscape world-wide) might have turned out quite differently had Cassirer lived long enough in his final country of destination, the United States, to establish a pool of students. ${ }^{2}$ Cassirer's children, had he had had more especially in America, might have shaped the face of philosophy differently and might have kept a grip on the mainstream of philosophy in the US,

2 Equally successfully, one can surmise, as other émigrés, such as Heidegger's children already mentioned, and others, such as Rudolf Carnap, Leo Strauss, and others. 
which came to dominate philosophy world-wide in the latter half of the twentieth century, following the paradigm of analytic philosophy. Indeed, it is not too farfetched to say that, with the presence of a balancing figure such as Cassirer in the mix, the hostile standoff between "continental" and "analytic" philosophy, which has polarized the scene since, might have altogether turned out less hostile or even would not have existed in this shape (at least) in the first place.

The present volume is meant to assess and appreciate for the first time the impact Cassirer has had on (some of) his students, his children, immediate or mediate, direct and indirect. Indeed, some of the people who may be identified as such children, developed their own approaches, some of which, one needs to add immediately, go beyond philosophy proper. But this does not diminish their status as Cassirer's offspring. For going beyond the narrow confines of philosophy is Cassirer's very philosophical program. Indeed, the work done by Cassirer's children goes into areas as diverse as philosophy of science, anthropology, ethnology, sociology, aesthetics and art history, intellectual history broadly construed, literature criticism, and beyond. All authors of this volume strongly assert (explicitly or implicitly) that this spread into different areas of scholarship is not accidental. Indeed, Cassirer's students have thereby taken up the very ethos of Cassirer's philosophy of culture, namely to not allow philosophy and philosophical questioning itself to be asked in isolation or kept locked up in an ivory tower. Cassirer liked to invoke Kant's famous words of the "rich bathos of experience" into which the philosopher should not be afraid of wading. As Cassirer has demonstrated time and again in his own work, such a distanced position from culture and the sciences devoted to it would be impermissible, even irresponsible. Indeed, it was the model Cassirer himself laid out in his own work in his philosophy of culture, to conceive the different areas of culture as symbolic forms, which call for an assessment and understanding through philosophy, conceived as a purely armchair affair, only in part, if not thoroughly inadequately. In turn, philosophy can only do its work in close conjunction with the respective sciences of these cultural "provinces." Conversely, a philosophy of culture can only come into existence in the first place with the input from the sciences of the respective cultural domains.

There is thus an intrinsically interdisciplinary element to Cassirer's philosophy, which is a research program, very much like the research program of phenomenology, set up by its founding father Edmund Husserl, to be carried out by generations after him-arguably more successful in the case of Cassirer. Cassirer's philosophy has its own distinct character, to be sure, but in this organizational, institutional aspect it is quite similar to that of phenomenology. While some of Cassirer's students did not work in philosophy proper and others did not, perhaps, properly acknowledge the philosophical background stemming from Cassirer as they could or should have, they nonetheless actively lived and furthered Cassirer's 
ethos, even if unbeknownst to them. We believe that it is, for the reasons mentioned, worthwhile to investigate the work of what we would like to call here, provocatively, Cassirer's Children.

If one were to give a list of intellectuals who would count as such children, one may take a preliminary look at the host of names assembled here. As the reader can see, there are papers on Susanne Langer, Edgar Wind, Arthur Pap, Hans Blumenberg, Eugenio Garin, Clifford Geertz, Nelson Goodman, Pierre Bourdieu, Jürgen Habermas, and philosophers in Japan belonging to the famous Kyoto School. Others who are not discussed here, but who deserve to be listed here and should also be studied in this respect (some more known than others), include, moreover, Gertrud Bing, Fritz Saxl, Ernst Hoffman, Clarence Smith Howe, Raymund Klibansky, Oskar Kristeller, Heinrich Levi, Joachim Ritter, Ruth Barcan Marcus, Talcott Parsons, James Pettegrove, Walter Schmitz, Eric Weil, and Max Wertheimer. And the list may be continued.

Back to Heidegger one last time. He has become a classic of the twentieth century not least due to his offspring. Cassirer, after being rediscovered in the last 20 years as another giant of the twentieth century, can now be fully reassessed not least through the meticulous historical-critical edition of his work, which is now complete. ${ }^{3}$ One way to honor a thinker is to edit his or her works in scholarly fashion, and in this respect, Cassirer has been honored to the highest degree. Now is the time to assess for the first time on a larger scale the influence Cassirer has had on generations of thinkers after him. If there can be some truth to the notion that Cassirer's philosophy as a philosophy of culture and a culture of philosophizing is a program that is not dated but something that can be taken up and pursued, especially in a culturally diverse time as ours and while "culture wars" are raging around is, then there could perhaps be no better the time to begin such an undertaking. To be sure, Cassirer's children have already done their work and have shown, and continue to demonstrate, Cassirer's livelihood. It is now up to contemporary scholars sympathetic to this philosophical program to take up the baton to retrace their steps and to see how a philosophy of culture in the manner in which Cassirer has bequeathed it to posterity, can be taken up and continued. Especially in today's philosophical scholarship, where cultural hegemonies are rightfully being challenged and aligned with political power structures, which oftentimes and all too rashly include the use of reason as well, a balancing figure like Cassirer might be a welcome voice. While explicitly being sympathetic to "non-Western" ways of culture, he nonetheless stood

3 Cassirer's critical edition of his published work (ECW) is completed; the critical edition of his literary estate (ECN) is as well as of 2021. The last ECN Vol. 13 is just appeared. Both multi-volume editions are published by Meiner (Hamburg). 
for a distinctly philosophical approach to cultural practices and their justification before the tribunal of an enlightened populace.

Children do not always do as their parents please, and sometimes they do the contrary of what their parents had wanted or wished for them. But this is not an argument against being a child. Sometimes children demonstrate their kinship in strange ways. But this, too, is part of someone's legacy, to remain present and influential in unusual and peculiar manners.

This volume bears witness to Cassirer's legacy in interesting, sometimes curious and less obvious ways.

Finally, the volume is supplemented by a mini-edition of a hitherto unknown manuscript, Cassirer's earliest draft of the systematics of the Philosophy of Symbolic Forms of 1917. This manuscript was discovered in Cassirer's literary estate at Yale by Arno Schubbach. This text, while published in the original in Schubbach's monograph of 2016, is published here for the first time in English translation (by D.J. Hobbs). Schubbach also supplied an interesting introduction to this text, which situates this text in the context of Cassirer's oeuvre, but also highlights some of the larger philosophical points one can derive from it.

Torino \& Cologne, Spring 2021 